\title{
A estabilidade da democracia e a cultura política no Uruguai: revisão a partir da ciência política uruguaia
}

Rodrigo Enrich de Castro ${ }^{\mathrm{I}}$ (D)

\section{Introdução}

Em uma região onde a cultura autoritária tem raízes profundas, que dificultaram a consolidação de regimes democráticos ao longo do século XX, o Uruguai é considerado uma das democracias mais estáveis (Selios, 2006, p. 64), configurando um caso excepcional dentro do contexto latino-americano, a democracia mais antiga e estável da América Latina (Buquet; Chasquetti, 2004), e um dos países com maior tradição democrática na América Latina, tendo sofrido apenas dois golpes de Estado, em 1933 e em 1973, sendo apenas este último com participação direta dos militares. Desde a redemocratização em 1984, o Uruguai tem mantido sua estabilidade democrática, com eleiçôes regulares, alternância pacífica de partidos no poder, sem golpes ou deposição de presidentes (mesmo durante a grave crise econômica e social de 2002) e sem mudanças constitucionais que permitissem a reeleição, como Carlos Menem na Argentina, Fernando Henrique Cardoso no Brasil e Hugo Chávez na Venezuela. Um bom exemplo dessa estabilidade pôde ser visto nas eleiçóes de 2019, quando o candidato Luis Lacalle Pou, do Partido Nacional, obteve apenas 37 mil votos a mais que o candidato da Frente Ampla, Daniel Martinez. Como os resultados iniciais não apontavam um vencedor claro o resultado final demorou cinco dias para ser publicado e não houve, de nenhuma das partes, qualquer tipo de denúncia de fraude, tão comum em outros países.
Tendo por base o acima exposto, quais fatores explicam que, em uma região marcada pela instabilidade política, o Uruguai mantenha uma democracia estável? Os primeiros trabalhos de interpretação acerca da democracia uruguaia datam de meados dos anos 1960 e tinham como foco de análise os partidos, o sistema eleitoral e a formação da classe média como fatores explicativos da estabilidade do regime democrático no Uruguai (Rama, 1969; Real de Azúa, 1984; Solari, 1967). A partir do final dos anos 1980 a ciência política se institucionalizou na academia uruguaia, com a formação do Instituto de Ciência Política, formando profissionais com conhecimento metodológico e teórico específicos da área. No entanto, o desenvolvimento da ciência política no país não correspondeu a uma mudança nas interpretaçóes dominantes sobre as causas da estabilidade democrática, dado que o enfoque se manteve nos partidos, sistemas eleitorais e na estrutura social.

Neste contexto, os trabalhos que relacionam a estabilidade da democracia com a cultura política, ou seja, com os valores, crenças e atitudes dos indivíduos, são minoritários. $\mathrm{O}$ objetivo deste trabalho é compreender as causas da estabilidade da democracia no Uruguai a partir de uma revisão da literatura de pesquisadores uruguaios. Para a melhor compreensáo do tema, inicialmente será apresentado o conceito de democracia. Em um segundo momento, analisaremos a literatura acerca da formação e estabilidade da democracia uruguaia realizada especificamente por

IPrograma de Pós-Graduação em Ciência Política, Universidade Federal do Rio Grande do Sul (UFRGS) - Porto Alegre (RS), Brasil. E-mail: rodrigo.enrich@ufrgs.br

Recebido em: 08/04/2020. Aprovado em: 20/06/2021. 
cientistas políticos uruguaios, destacando, ao final, os autores uruguaios que trabalham com a estabilidade da democracia a partir de sua relação com a cultura política uruguaia.

\section{Democracia e estabilidade democrática}

No século XX Schumpeter, em uma definição minimalista, caracteriza a democracia não como um ideal, mas como um método, "um sistema institucional para a tomada de decisóes políticas no qual o indivíduo adquire o poder de decidir mediante uma luta competitiva pelos votos do eleitor" (Schumpeter, 1961, p. 328). De acordo com Schumpeter, há quatro condiçôes necessárias para o êxito do método democrático: 1) a qualidade do material humano da política, que deve ser suficientemente alta, ou seja, políticos devem ser qualificados; 2) o campo real das decisóes não pode ser demasiadamente amplo, um Estado limitado em suas atividades; 3) uma burocracia bem treinada e com sentido de dever; e 4) o "autocontrole democrático", ou seja, a aceitaçáo das medidas legislativas e das ordens do governo (Schumpeter, 1961, p. 352-357).

Dahl caracteriza a democracia, identificada como "poliarquia", como um sistema de governo em que todos os cidadáos têm iguais oportunidades de formular suas preferências, de manifestá-las publicamente e de receberem tratamento igual por parte do governo, sem nenhum tipo de discriminação (Dahl, 1997). Para que esses requisitos possam ser satisfeitos, é necessária a existência das seguintes garantias institucionais: liberdade de associaçáo; de expressão; de voto; liberdade de competição entre as lideranças políticas na busca de apoio; diversidade de fontes de informação; eleiçôes livres e imparciais e instituiçóes que garantam que a política do governo dependa dos votos (Dahl, 1997, p. 14-15).

No entanto, não somente é importante definir o conceito de democracia quanto entender porque algumas democracias são mais estáveis que outras. Em relação ao conceito de estabilidade, Morlino afirma que "estabilidade é a capacidade previsível que um sistema tem de se prolongar no tempo" (Morlino, 2016, p. 394) e que é necessário não confundir estabilidade com imobilismo, dado que um determinado sistema é estável justamente por sua capacidade de adaptar-se às adversidades. Antes de entrar nas explicaçôes sobre a estabilidade da democracia uruguaia, é necessário repassar alguns dos principais trabalhos sobre a estabilidade democrática de modo geral. Muitos pesquisadores têm se preocupado em analisar os fatores que contribuem para a estabilidade da democracia. Para Dahl a democracia requer algumas condiçóes essenciais, como controle dos militares por autoridades eleitas; cultura política e convicçôes democráticas; ausência de controle estrangeiro hostil à democracia; uma sociedade, economia de mercado e fracas divisóes culturais (Dahl, 2001, p. 163).

Lipset realiza uma análise comparada entre diversos países e encontra uma forte correlação entre níveis de riqueza, educação e urbanizaçáo, legitimidade institucional e estabilidade democrática, ou seja, quanto maior o desenvolvimento econômico maior a probabilidade de o país desenvolver uma democracia estável (Lipset, 1959). Przeworski, a partir de estudo com dados anuais de 135 países entre 1950 (ou o ano da independência ou o primeiro ano com dados econômicos disponíveis) e 1990, afirma que fatores econômicos como riqueza, crescimento com inflação moderada, desigualdade decrescente, e fatores institucionais, como sistemas parlamentaristas e um clima internacional favorável são os fatores que explicam a estabilidade da democracia (Przeworski et al., 1996, p. 113).

Por outro lado, dentro da perspectiva da cultura política, Almond e Verba afirmam que a estabilidade da democracia depende 
de determinados valores culturais presentes na sociedade, e que a cultura política mais apropriada a um regime político democrático, eficaz e estável é a cultura cívica (Almond; Verba, 1970, p. 550). Para os autores, uma cultura cívica é uma cultura política mista, na qual se encontram três tipos de cultura política: paroquial, súdita e participante. Uma cultura paroquial seria mais congruente com uma estrutura política tradicional, uma cultura súdita seria congruente com uma estrutura autoritária centralizada e uma cultura participante com uma estrutura política democrática (Almond; Verba, 1970, p. 38). Desse modo, em uma cultura cívica, esses três tipos de cultura política se combinam, de forma que o indivíduo participa do processo político, valoriza positivamente as estruturas e processos, sem abandonar suas orientaçóes súditas ou paroquiais. Essa moderação é o que faz com que a democracia seja estável ao longo do tempo.

Putnam identifica quatro dimensôes da comunidade cívica: participação cívica; igualdade política; solidariedade, confiança e tolerância; e as estruturas sociais da cooperação, identificando uma forte relação entre o desempenho institucional e a existência da comunidade cívica, sendo as regiôes com maior eficiência institucional aquelas com maior comunidade cívica. $\mathrm{O}$ autor afirma que "a comunidade cívica se caracteriza por cidadãos atuantes e imbuídos de espírito público, por relaçôes políticas igualitárias e por uma estrutura social firmada na confiança e na colaboraçáo" (Putnam, 1996, p. 30-31) e encontra fortes relaçôes entre o desempenho institucional de certas regiōes italianas e a existência da "comunidade cívica". Para Putnam, portanto, uma democracia será mais eficaz e estável à medida que mais "cívicos" e participativos forem seus cidadãos.

De acordo com Inglehart e Welzel, que analisaram dados de 81 sociedades coletados entre 1981 e 2002 e elaboraram uma revisão da teoria da modernização, o desenvolvimento socioeconômico leva a uma mudança cultural que, segundo os autores, "fazem da democracia o resultado institucional lógico" (Inglehart; Welzel, 2009, p. 18). No entanto, essas mudanças só ocorrem quando o desenvolvimento socioeconômico é sustentável. Para Inglehart e Welzel o desenvolvimento socioeconômico "diminui as restriçôes objetivas à autonomia, à criatividade e à escolha humanas" através: da redução da pobreza e do aumento do sentimento de segurança existencial; aumento do nível de educaçáo formal e do acesso à informação e aumenta a complexidade social, diversificando as interações (Inglehart; Welzel, 2009, p. 46). Segundo os autores, a industrialização gera a substituição dos valores tradicionais por valores "seculares-racionais", e o desenvolvimento para uma sociedade pós-industrial provoca uma mudança de valores de sobrevivência para os valores de autoexpressão. Contudo, mesmo com o desenvolvimento econômico, a tradiçẫo cultural das sociedades não desaparece, ao contrário, "os valores continuam a refletir a herança histórica de uma sociedade" (Inglehart; Welzel, 2009, p. 41). Os autores concluem que o desenvolvimento socioeconômico fortalece os valores de autoexpressão que tornam a democracia mais efetiva. Assim, as aspirações de liberdade são os valores mais relevantes para a democracia, dado que "a democracia funciona melhor em uma cultura que valoriza a escolha humana" (Inglehart; Welzel, 2009, p. 311), mais do que o simples apoio ao regime democrático ou a confiança nas instituiçôes.

Como visto acima são muitas as hipóteses que buscam explicar as causas da estabilidade da democracia. Sendo o Uruguai um caso excepcional no contexto latino-americano, quais são as principais explicaçôes, dentro da ciência política uruguaia, para a democracia no Uruguai? 


\section{Democracia e estabilidade no Uruguai}

Para compreender a construção da democracia no Uruguai faz-se necessário um breve resumo sobre a história política uruguaia do século XX. O Uruguai das primeiras décadas do século $\mathrm{XX}$ foi pioneiro na legislação social, com leis que favoreciam as mulheres e crianças, e trabalhista, sendo considerado a "Suíça da América Latina" (Nahum, 2011). O período foi marcado pelas políticas desenvolvidas inicialmente pelo presidente José Batlle y Ordońez, conhecido como batllismo, essencial para compreender o Uruguai no século XX, até o golpe de estado de 1933 e no pós-segunda guerra, com políticas de incentivo à industrialização até finais da década de 1950, o chamado neobatllismo (D'Elía, 1982; Frega, 2008; Nahum, 2004; Ruiz, 2008).

O período do batllismo marcou a política uruguaia e deixou marcas profundas na cultura política do país, que se prolongaram durante todo o século XX (Caetano, 2010). Para Moreira, o batllismo é "o fundamento da cultura política urbana e laica, com fortes referências ao Estado" e também "o reservatório cultural e moral mais importante do Uruguai" (Moreira, 1997, p. 76-77). De acordo com Frega, as políticas do período tinham como metas a utilização do Estado como indutor do desenvolvimento industrial e de reduçáo das desigualdades, através da implementação de políticas como nacionalização e estatização dos serviços públicos, incentivos à indústria, entre outras (Frega, 2008, p. 31-40).

Nahum aponta também outras políticas que marcaram o período, como a aprovaçáo da jornada de trabalho de oito horas, estatização do Banco República e outras empresas, universalizaçáo da educaçấo secundária, lei de divórcio, separação entre Estado e a Igreja Católica
(Nahum, 2004). Para Caetano, o imaginário criado na época do batllismo era baseado na predominância do "público" sobre o privado, uma "matriz democrático-pluralista de base estatista e partidocêntrica" (Caetano, 2010, p. 163), predomínio do mundo urbano e do cosmopolitismo eurocêntrico, exaltação do legalismo e o mito de uma sociedade "hiperintegrada”, produzindo assim certo imaginário coletivo que caracterizaria o Uruguai durante o século XX (Caetano, 2010).

De Sierra analisa o período do batllismo (1900-1930) menos como uma ruptura com o passado do que como uma etapa da formação social capitalista dependente no Uruguai, o que ocorreu, segundo o autor, entre 1870 e 1955 (De Sierra, 2017, p. 38). De Sierra divide o período em três fases: a primeira entre $1870 \mathrm{e}$ 1900 que seria a consolidaçáo do modo de produçáo capitalista, a segunda entre 1900 e 1930, de crescimento do capital agrário e a última entre 1930 e 1955 marcada pelo impulso à industrialização (De Sierra, 2017, p. 39-40). Acerca das características principais do período batllista, o autor afirma que as fraçôes comerciais e industriais urbanas conseguiram o domínio político no período a partir de uma aliança com a pequena burguesia, enquanto o setor agroexportador perde o poder político, mas mantém sua hegemonia econômica (De Sierra, 2017, p. 42). esse afastamento da política em relaçáo à economia tornou possível que "a luta econômica não seja vivida como luta de classes" (De Sierra, 2017, p. 43).

No entanto, a economia uruguaia era demasiadamente dependente da exportaçáo de produtos primários e com um limitado mercado interno, fatores que levaram o país a enfrentar sérios problemas econômicos a partir do final dos anos 1950 e que se agravariam durante os anos 1960 (de acordo com Nahum, 
a inflação foi de $135 \%$ em 1967), somado ao intenso conflito social e ao aumento da repressão estatal. Uma nova constituição foi aprovada em 1967, mas os problemas econômicos e sociais se aprofundaram, desembocando no golpe militar de 1973. Do ponto de vista econômico a ditadura foi bastante negativa especialmente para os setores produtivos, para os trabalhadores, além de ter deixado como herança uma grande dívida externa (Nahum, 2004, p. 325-359). O período militar marcou, portanto, o começo da aplicação de políticas neoliberais no Uruguai, com a diminuição das atribuiçôes do Estado, tanto na economia quanto no plano social.

Em 1980, o regime militar propôs um plebiscito que teve como objetivo consolidar a legislação criada durante o período militar e que também serviria como uma forma de aprovação do regime. A maioria da populaçấo (57\%) votou contra o regime, e assim teve início a transição democrática no Uruguai. Após a derrota no plebiscito, os militares iniciaram conversas com alguns dirigentes dos partidos tradicionais, embora com a relutância de setores do Partido Nacional, resultando no Pacto do Clube Naval, no qual foi estabelecido um período de três anos até a próxima eleição para a presidência e a autorização para o funcionamento dos partidos políticos.

Em 1985, o colorado Julio Maria Sanguinetti foi eleito presidente, tendo que enfrentar os graves problemas econômicos e sociais deixados pela ditadura. Durante seu governo foi aprovada a Ley de Caducidad, eximindo os militares da responsabilidade pelas violações de direitos humanos cometidas durante a ditadura. O governo Sanguinetti foi marcado por uma leve recuperação econômica, com um crescimento anual de 4,5\% entre 1985 e 1989, e por uma inflação ainda descontrolada de $71 \%$ ao ano (Nahum, 2011).

Em novembro de 1989 foi eleito presidente o candidato do Partido Nacional
Luis Alberto Lacalle. Sem a maioria no congresso, Lacalle fez acordos com setores do Partido Colorado e com boa parte do Partido Nacional, a denominada coincidencia nacional, para poder aprovar as reformas que julgava serem necessárias para a recuperação econômica do país. As reformas propostas seguiam as recomendaçôes do Consenso de Washington, ou seja, redução do tamanho do Estado, privatização de empresas do Estado, forte abertura comercial e cortes na legislação trabalhista. As privatizaçôes começariam pelas empresas Antel (telecomunicações) e Pluna (aviação civil). No entanto, com uma intensa mobilização dos sindicatos, da oposiçáo e de um setor do Partido Colorado, em 1992 foi realizado um plebiscito para impedir a privatizaçáo de empresas públicas e $70 \%$ da população votou contra as privatizaçóes (Departamento de Historia del Uruguay, 2008; Rial, 1998). Com um massivo posicionamento contrário às privatizaçóes o governo Lacalle começou a perder uma parte do apoio no congresso e não pôde realizar as reformas neoliberais que desejava.

Em 1994, foi eleito o ex-presidente Julio Maria Sanguinetti que, também sem maioria no congresso, teve que negociar apoio de setores do Partido Nacional. O governo Sanguinetti conseguiu aprovar uma reforma constitucional em 1996. Essa reforma acabava com a possibilidade de os partidos apresentarem mais de um candidato à presidência, instituía o segundo turno (balotaje), a separaçáo entre a eleição presidencial e as municipais, entre outras mudanças. Também foram aprovadas as reformas da educação, focada principalmente na educação pré-escolar, e a reforma da previdência. De acordo com Nahum (2011), desde o fim da ditadura, todas as políticas impulsionadas tanto pelos governos blancos quanto colorados tinham como objetivo final a diminuição das atribuiçôes do Estado e sua importância na sociedade. Apesar da queda 
da inflação (de 15\% em 1997 a 4\% em 1999) e da leve queda do desemprego, o índice de pobreza se manteve alto (Nahum, 2011).

Em resumo, os anos 1990 foram marcados pelo aprofundamento das políticas neoliberais no Uruguai, com privatizaçóes de empresas públicas, diminuição das funções do Estado, abertura comercial e desregulamentação do mercado de trabalho, além de reformas importantes na educação, seguridade social e no sistema político e eleitoral (Departamento de Historia del Uruguay, 2008; Nahum, 2004). Nas eleiçóes de 1999, foi eleito o colorado Jorge Batlle, sendo o primeiro presidente eleito pelo sistema de balotaje (segundo turno) instaurado em 1996. Com pouco apoio parlamentar, Batlle construiu uma aliança instável com o Partido Nacional. No final de 2001, a crise argentina atinge seu auge, com sérias consequências para a economia uruguaia a partir do ano seguinte, e o governo Batlle teve que enfrentar aquela que é considerada a maior crise da história do país.

Nas eleiçóes de 2004, depois de uma grave crise econômica e social (Nahum, 2004; Oyhantçabal, 2019), o Uruguai elegeu pela primeira vez em sua história um partido de esquerda para o governo nacional, sendo reeleito em 2009 e 2014. A chegada da Frente Ampla ao governo marcou o começo daquilo que Yaffé e Garcé chamaram de "era progressista" (Garcé; Yaffé, 2014), que terminou em 2019, com a vitória do Partido Nacional nas eleições. Durante os dois primeiros governos houve crescimento do PIB, aumento de salários, ampliaçáo de direitos sociais, a implementaçáo de uma importante reforma no sistema de saúde e na educação, e o desemprego caiu, assim como a pobreza (Bentancur; Busquets, 2016). Entretanto, durante o último período de governo (2015 2020), fatores como um caso de corrupção envolvendo o vice-presidente Raúl Sendic, que renunciou ao cargo, o aumento da insegurança e o estancamento da economia causaram um desgaste na Frente Ampla (Caetano; Selios; Nieto, 2019), que nas eleiçóes de 2019 perdeu o governo para o Partido Nacional, e no segundo turno teve que aliar-se ao Partido Colorado, ao Partido Independiente, ao Partido de la Gente e ao novo partido Cabildo Abierto, liderado por um general aposentado que havia sido comandante das forças armadas durante $o$ último governo da Frente Ampla.

Em relação às interpretaçôes sobre a democracia uruguaia, pelo menos desde a segunda metade do século XX são realizados estudos a partir de uma abordagem sociológica, como Solari (1967), Rama (1969) e Real de Azúa (1984), leituras obrigatórias para a compreensão da política uruguaia no século XX (Garcé, 2005). Outros pesquisadores destacados desse período são Antonio Grompone, Carlos Martínez Moreno e Carlos Quijano (De Sierra, 2006, p. 322). Aldo Solari destaca-se além dos seus escritos por ter sido diretor do Instituto de Ciências Sociais entre 1963 e 1967 e por ter organizado, juntamente com Lipset, um livro sobre as elites na América Latina (De Sierra, 2006, p. 324.) De Sierra afirma que esse primeiro período fundacional das ciências sociais no Uruguai foi marcado por um paradoxo, qual seja,

\footnotetext{
"por um lado, um atraso (em comparação com a regiāo) da consolidação e institucionalização das ciências sociais...E por outro, um alto grau de maturidade, e mesmo uma precocidade, da estrutura e qualidade universitária nos âmbitos 'profissionais' clássicos” (De Sierra, 2006, p. 321).
}

Dentro dessa primeira fase, anterior à institucionalização da ciência política, Solari enfoca no sistema de coparticipaçáo no governo e nos acordos e compromissos entre as fraçóes dos dois partidos tradicionais. Nesse sentido "se a essência da democracia é o consenso, seria difícil encontrar um regime mais 
democrático que o uruguaio"2 (Solari, 1966, p. 122). Solari também considera o sistema de partidos então existente como funcional para diminuir as tensôes sociais e garantir a estabilidade política (Solari, 1966, p. 136).

Do mesmo modo, reforçando a importância dos acordos entre elites e dos partidos na política uruguaia, Rama identifica a estabilidade democrática com a mobilização eleitoral realizada pelos partidos. $\mathrm{O}$ autor afirma também que a estabilidade deve-se a fatores estruturais da sociedade uruguaia, como a integração e a mobilidade social, ambas produtos da educação pública, e a política de consenso entre líderes políticos, assim "é a presença de participaçáo política, mobilidade social, de expectativas favoráveis de acesso à educação e à bens, da transmissão de uma imagem positiva da sociedade nos processos de socializaçáo familiar e através do sistema educativo institucional"3 (Rama, 1969, p. 74).

Real de Azúa reflete sobre o Uruguai da primeira metade do século XX a partir de uma análise da política desenvolvida pelo presidente José Batlle y Ordónez e seus herdeiros políticos, o Batllismo. Para o autor, o batllismo, que tanto colaborou para o desenvolvimento do Uruguai, continha em si as limitaçóes que acabariam levando o país à crise dos anos 1960 (Real de Azúa, 2009). Real de Azúa lembra que o Uruguai surgiu como um estado-tampão, um "algodáo entre cristais", entre o Império brasileiro e a confederação Argentina, característica que tornou o país uma "sociedade amortiguadora", amortecedora de conflitos, com baixas tensóes sociais, ao menos como tendência dominante, onde os conflitos sociais não chegam a explodir, dado que em algum momento surge uma solução de compromisso (Real de Azúa, 1984). Além de relevante produção acerca do processo de formaçãa histórica das origens da nacionalidade uruguaia, do Estado e de suas elites, Real de Azua teve também importante participação nos debates políticos e acadêmicos da época, sendo considerado um dos autores que teve mais impacto na ciência política uruguaia posterior (De Sierra, 2006; Mallo, 2012).

Em relação à relevância da classe média para a estabilidade política uruguaia, a obra pioneira é de Bauza (1876), tendo alguns autores defendido essa postura a partir de estudos sobre a formação precoce e a importância da classe média uruguaia durante o século XX (Errandonea, 1969; Rama, 1969; Solari, 1956).

Durante o período da ditadura militar (1973-1985) solidificou-se um campo privado de pesquisa nas ciências sociais através dos centros de pesquisa mantidos essencialmente com financiamento externo ${ }^{4}$ (De Sierra, 2006, p. 332-333). Com a volta da democracia, muitos pesquisadores que atuaram nos centros voltaram à universidade e outros mantiveram suas atividades profissionais privadas, embora com forte diminuição do financiamento externo dos centros (De Sierra, 2006, p. 337-344). Em relação ao crescimento da ciência política De Sierra afirma que as análises políticas eram produzidas basicamente pela sociologia política e pela história política e que, apenas em 1989, foi criado o curso de licenciatura em ciências políticas (De Sierra, 2006, p. 331).

Portanto, a ciência política uruguaia teve um desenvolvimento tardio (Garcé, 2005), dado

2 Tradução nossa.

3 Tradução nossa.

4 De Sierra (2006) destaca o Centro Latino-Americano de Economia Humana (Claeh), o Centro de Pesquisas Pedagógicas (Ciep), Centro de Informaçōes e Estudos do Uruguai (Ciesu), Centro de Pesquisas Econômicas (Cinve), entre outros. 
que foi somente com a volta da democracia em 1985 que se formou o Instituto de Ciência Política (ICP) da Universidade da República, dando início à formação acadêmica na área de ciência política (Buquet, 2012; De Sierra, 2006; Garcé, 2005). Desse modo, foram selecionados trabalhos publicados entre 1985 e 2019 de pesquisadores uruguaios, portanto, o trabalho não é de modo algum uma revisão exaustiva de todos os trabalhos já realizados sobre o tema, dado que existem outras publicaçóes que náo são analisadas neste trabalho ${ }^{5}$, cujo enfoque é nos trabalhos da Revista Uruguaya de Ciencia Política (RUCP) e também de pesquisadores que trabalham na academia uruguaia. Foram selecionados apenas aqueles que abordam especificamente a estabilidade da democracia uruguaia, publicados no Uruguai e em outros países. A partir da busca pela palavra "democracia" na Revista Uruguaya de Ciencia Politica (RUCP), principal da publicação do país na área, foram encontrados 40 artigos, sendo 19 referentes à democracia uruguaia e apenas seis cujo foco é algum tipo de explicaçáo sobre a formação ou a estabilidade da democracia. Dos demais trabalhos aqui analisados seis são livros, dois são publicaçôes acadêmicas uruguaias (Documentos de Trabajo e Cuadernos del $C L A E H)$ e dois foram publicados em periódicos de outros países (Chile e Espanha).

Em oito dos trabalhos analisados, os fatores que contribuíram para a formação e a estabilidade da democracia no Uruguai são a durabilidade do sistema partidário e sua relevância na sociedade, a chamada partidocracia e os pactos de governabilidade entre as elites que resultaram na promulgação da constituição de 1918, considerada como marco inicial da "poliarquia" no Uruguai. Neste sentido,

\begin{abstract}
"As mais comuns interpretaçôes históricas e políticas de nossa democracia privilegiaram o papel dos partidos tradicionais por sua centralidade política, por sua vocação para estabelecer acordos e sua capacidade para gerir a condução do país, particularmente através do expediente da coparticipação, isto é, da distribuição das posições de governo e da cogestão"'6 (Buquet; Chasquetti, 2004, p. 232).
\end{abstract}

Portanto, as explicaçóes que utilizam variáveis relativas à cultura política são minoria. Parece consenso entre os cientistas políticos aqui analisados que a Constituição de 1918 marcou o início da poliarquia no Uruguai, com a implementação do sufrágio universal masculino, representaçáo proporcional para o legislativo, voto secreto e inscrição obrigatória no registro eleitoral (Buquet; Moraes, 2018).

De acordo com De Sierra o que permitiu a estabilização da democracia foi "o caráter laico e liberal das fraçôes burguesas modernizadoras que foram hegemonizando o bloco no poder desde o começo deste século e o grande excedente agropecuário exportável"7 (De Sierra, 1998), acrescentando a variável econômica à análise. De Sierra também aponta que os partidos tradicionais foram fatores estabilizadores do sistema. Da mesma forma, Pérez afirma que a Constituição de 1918 foi uma "complexificação do consenso", produto do acordo entre as elites partidárias tradicionais, que vinham-se desenhando desde o último quarto do século XIX (Pérez, 1988). Lanzaro utiliza o conceito de democracia consensual de Lijphart para definir o Uruguai do século XX, além de ser uma democracia pluralista e poliárquica (Lanzaro, 2004). Uma das características da democracia consensual é a participaçáo de todos os partidos importantes no poder, estimulando o consenso e a inclusão

\footnotetext{
5 Por exemplo, publicaçóes da Revista de Ciências Sociales.

6 Tradução nossa.

7 Tradução nossa.
} 
(Lijphart, 2008, p. 54), exatamente como acontecia no Uruguai do século XX. O enfoque de Lanzaro está inicialmente nas regras eleitorais, como a lei de lemas e a representação proporcional, bem como a coparticipação entre os dois partidos tradicionais no governo como base da unidade do Estado. Desse modo, afirma $o$ autor que

"a estrutura democrática é favorecida por certos tra-
ços originários do espaço em que ocorre a construção
nacional. Mas responde à forma específica em que
se desenvolve a dinâmica política e, em particular,
às modalidades concretas do sistema de partidos e
seus modos de relação, os códigos de competição,
o princípio de coparticipação e o regime eleitoral
que irão construir"s (Lanzaro, 2004, p. 104-105).

Para Caetano, Rilla e Pérez (1987) o enfoque está no que os autores consideram uma singularidade do caso uruguaio: a centralidade dos partidos como atores políticos dominantes, chamada de partidocracia. O termo partidocracia surgiu no pós-segunda guerra europeu como uma crítica dos liberais para designar a expansão e o domínio dos partidos de massa (Pasquino, 2016, p. 905). Para os liberais europeus de então, a representação individual estava em perigo devido à crescente presença dos partidos na política. Desse modo, o termo designa não apenas o predomínio dos partidos de massa na política, mas também na vida econômica e social, que poderia produzir seu controle sobre toda a sociedade (Pasquino, 2016, p. 906). A partir dos anos 1970 é a esquerda que passa a criticar a partidocracia, apontando o caráter conservador dos partidos e a falta de espaço da sociedade civil na política. Especificamente no contexto italiano apontado por Pasquino, mas que pode ser aplicado a outros países, são dois os principais instrumentos políticos que fortalecem a partidocracia: o financiamento público dos partidos e a predominância de critérios políticos para cargos em diversos setores da sociedade e da economia. Esse seria o caso, segundo Caetano et al., da democracia uruguaia. No entanto, os autores veem a partidocracia como fator de estabilidade do sistema político, e sua relevância está ligada a outras características da sociedade uruguaia, como

\footnotetext{
"Uma estratificação social que revela historicamente baixos níveis de tensóes interclassistas, um Estado tradicionalmente inclusivo e relativamente autônomo, um elenco político com fortes índices de adensamento grupal e persistência, uma cultura política mesocrática e fortemente referida à postulação de uma 'república de cidadãos'”' (Caetano; Rilla; Pérez, 1987, p. 42).
}

Entretanto, o sistema partidário uruguaio não seria absolutamente estável, mas mostraria uma persistência com mudanças e através das mudanças (Caetano; Rilla; Pérez, 1987).

Através do estudo da evoluçáo eleitoral do Uruguai no século XX, Errandonea busca analisar o desenvolvimento do sistema político uruguaio do período e de suas características, como a participação política, o sistema de partidos, os próprios partidos, os líderes políticos e a ideologia da população (Errandonea, 1994, p. 19). O autor afirma que até meados dos anos 1950 o Uruguai foi a sociedade mais progressista e estável da América Latina, caracterizando-se por decisóes políticas derivadas de acordos entre os partidos tradicionais, por um "bipartidarismo eleitoral e multipartidarismo cotidiano" devido à existência de importantes divisóes internas nos partidos, a legitimação das consultas populares como instrumentos de ação política, entre outros (Errandonea, 1994, p. 65).

$8 \quad$ Tradução nossa.

9 Traduçáo nossa. 
Buquet e Chasquetti concordam com as interpretaçôes de que a Constituiçáo de 1918 marcou o início da poliarquia no Uruguai, enfocando nas reformas eleitorais e na importância dos partidos e dos acordos políticos para a estabilidade democrática, chamada pelos autores de "partidocracia de consenso", assim "o nascimento da democracia uruguaia é uma operação concertada entre os partidos e sua manutenção dependia, e talvez ainda dependa, da manutenção desse mesmo acordo"10 (Buquet; Chasquetti, 2004, p. 227). Os autores identificam três momentos poliárquicos no Uruguai, o primeiro a partir da Constituição de 1918 até o golpe civil de 1933; o segundo entre 1942 e o golpe militar de 1973; e o último a partir da redemocratização em 1985. Sobre o atual período poliárquico uruguaio, os autores afirmam que este se mantém estável porque os partidos retomaram o domínio da política depois da democratização, mas também pela adesão dos uruguaios aos valores democráticos, utilizando dados da pesquisa Latinobarômetro. Neste texto as variáveis de cultura política são citadas apenas no final do texto e de forma superficial. A relevância da constituição de 1918 como marco da democracia uruguaia foi tema de um número especial da RUCP em 2018, organizado por Jorge Lanzaro, fundador do Instituto de Ciência Política. Em artigo publicado nesse número especial, Buquet e Moraes reforçam a interpretação da origem da democracia uruguaia através de acordos entre as elites políticas do início do século XX, tornando o consenso uma norma constitucional a partir de 1918 (Buquet; Moraes, 2018).

Para Lanzaro e De Armas, as elites políticas do Uruguai do início do século XX acreditavam que o desenvolvimento da classe média favoreceria a estabilidade política, bem como o desenvolvimento econômico e assim o estabelecimento do Uruguai como um "país modelo" (Vanger, 1980). Os autores apontam para as condiçóes estruturais consideradas ideais para o surgimento de uma classe média no Uruguai, como a implementaçáo de um sistema educativo público, laico e gratuito desde finais do século XIX e a debilidade de poderes que em outros países tiveram grande influência, como a Igreja católica, as oligarquias econômicas e o exército. Já a expansão dessa classe média durante a primeira metade do século XX foi produto, entre outros fatores, da expansão do Estado e consequente aumento do número de funcionários públicos. Em relação aos partidos, os autores afirmam que os dois partidos tradicionais foram catch all desde o início, dado que "historicamente não houve no Uruguai uma correlação simples entre classe e voto. Todos os partidos são policlassistas e as classes sociais têm distribuído seus votos entre eles"11 (Lanzaro; De Armas, 2012, p. 42). O conceito de partido catch all foi desenvolvido por Kirchheimer para se referir aos partidos europeus do pós-segunda guerra, quando os partidos de massa estavam "se concentrando mais completamente no cenário eleitoral, na tentativa de trocar a efetividade do debate mais aprofundado por uma audiência mais ampla e pelo sucesso eleitoral mais imediato" (Kirchheimer, 2012, p. 362), ou seja, tentando atrair uma base eleitoral maior, que abarcasse todas as classes sociais.

Como visto acima, mesmo após o início do desenvolvimento da ciência política e consequentes atualizaçóes teórico-metodológicas, a democracia uruguaia ainda é estudada através das perspectivas iniciadas nos anos $1960 \mathrm{e}$ 1970 , salvo algumas pesquisas realizadas com

\footnotetext{
10 Tradução nossa.

11 Tradução nossa.
} 
a utilização de pesquisas de opiniáo. Utilização de análises estatísticas, teoria dos jogos, apenas foram utilizadas para reforçar hipóteses existentes. As causas da limitação a hipóteses anteriormente desenvolvidas náo entram no escopo deste trabalho.

\section{Cultura política e democracia no Uruguai}

Os estudos de opinião pública no Uruguai têm cada vez mais prestígio, especialmente em períodos eleitorais, com ampla divulgação nos meios de comunicação e com a participação de analistas e cientistas políticos (Garcé, 2005). Entretanto, a maioria das pesquisas são realizadas por empresas privadas, com pouca participação do mundo acadêmico (Rocha, 2012) e priorizam processos eleitorais. Assim, os estudos de cultura política no Uruguai são restritos ao comportamento eleitoral e análises de resultados eleitorais, sendo minoritários aqueles que trabalham com variáveis culturais como explicação sobre a estabilidade da democracia.

César Aguiar foi o pioneiro das pesquisas de opiniáo pública no Uruguai (Zuasnabar, 2018a). Em obra organizada por Jorge Lanzaro em 2018 sobre a produção de Aguiar destacam-se dois textos sobre opiniáo pública no Uruguai. O primeiro artigo, de 1987, defende a utilização das pesquisas de opiniáo para estudar diferentes aspectos dos partidos políticos (Aguiar, 2018a). No segundo texto, de 2000, Aguiar utiliza dados eleitorais e pesquisas de opinião pública para analisar as eleiçóes de 1999 a partir de três perspectivas: uma de longo prazo, começando com a crise do modelo de industrialização por substituição de importaçôes, no final dos anos 1950; uma de médio prazo, a partir da redemocratização em meados dos anos 1980; e a de curto prazo, cujo foco é a campanha de 1999 (Aguiar, 2018b). Para o autor, ao contrário do que se acreditava, não houve uma "esquerdização" do eleitorado uruguaio, mas sim um processo no qual a Frente Ampla foi atraindo os eleitores mais ao centro do espectro político, bem como o "efeito demográfico", ou seja, "em um eleitorado dividido por idade, mesmo que ninguém mude de opiniáo, a simples passagem do tempo implica um crescimento dos partidos que tem maior peso relativo entre os eleitores mais jovens" ${ }^{12}$ (Aguiar, 2018b), o que explicaria o crescimento da Frente Ampla entre 1971 e 1999.

González faz uma análise do efeito que os fatores político-institucionais exercem sobre a estabilidade democrática uruguaia e afirma que, no curto prazo, a estabilidade depende em grande parte da vontade da elite política e da qualidade de sua atuação (González, 1993, p. 18-19). Por outro lado, o autor afirma que o sistema eleitoral produzia fortes divisóes internas nos partidos e polarizaçáo política e tiveram impacto significativo nas rupturas democráticas, tanto em 1933 quanto em 1973, somado à fortes crises econômicas e sociais. Dessa forma, de acordo com a análise de González, a estrutura política que foi funcional ao estabelecimento da democracia não favoreceu sua estabilidade. É apenas na parte final do trabalho que González expóe os dados de duas pesquisas de opiniáo: a primeira realizada em Montevidéu em 1985, e uma segunda pesquisa feita com legisladores em 1986. Comentando os dados da primeira pesquisa, o autor afirma que os partidos uruguaios historicamente foram catch all, mas que naquele momento em que foi feita a pesquisa estava ocorrendo uma mudança significativa, sendo os três partidos cada vez mais classistas, indo de encontro à tendência dos partidos nas 
demais democracias (González, 1993, p. 203). $\mathrm{Na}$ segunda pesquisa é analisada a opiniáo de legisladores de todos os partidos sobre a importância da democracia, apoio à liberdade política, apoio ao igualitarismo político, apoio ao presidencialismo etc. González aponta diferenças entre os políticos dos três partidos, mas uma ampla maioria defendia a democracia como melhor sistema político para o país, apoiava a liberdade política e o igualitarismo.

Assim, González utiliza os dados de cultura política apenas como ilustração do momento político de volta da democracia no Uruguai e aponta possíveis perspectivas para a democracia, já que o ponto central de seu argumento se encontra nas estruturas políticas e nas açóes das elites políticas. Do mesmo modo, Moreira também analisa a cultura política uruguaia, mas com dados da pesquisa Latinobarômetro de 1995 e comparando com dados do Brasil, Argentina e Chile, mostrando que a populaçáo uruguaia tinha maior adesão aos valores democráticos e às instituiçôes políticas.

Moreira também faz uma análise comparativa da cultura política da sociedade com a das elites políticas, concluindo que havia uma forte homogeneidade entre a cultura política da população e das elites, especificamente nas variáveis preferência pela democracia, atitudes em relação às instituiçôes políticas e atitudes em relação à dimensão Estado e mercado (Moreira, 1997, p. 180). Uma das virtudes do trabalho de Moreira é a análise de grande número de variáveis, aproximadamente 40 . Entretanto, um aspecto relevante do trabalho é que a autora afirma que a democracia uruguaia contradiz algumas das teorias liberais da democracia (Moreira, 1997, p. 67). Por exemplo, o fato de que o país contraria as interpretaçóes de que o fracasso das democracias na América
Latina deve-se à cultura ibérica ou à herança hispânica. Ao nosso ver, o Uruguai náo chega a contradizer essa teoria, pois o país foi marcado justamente por uma debilidade, se não ausência, de um dos principais elementos da herança ibérica, a saber, a Igreja Católica. Moreira afirma que, segundo a teoria tocquevilliana, a centralização governamental é contrária à participação dos cidadáos na política, e que no caso uruguaio o que ocorreu foi o oposto, tendo a cultura democrática sido gerada a partir do próprio Estado, com forte participação dos partidos políticos (Moreira, 1997, p. 67-68). A teoria de Almond e Verba, segundo a qual a moderação partidária dos cidadãos seria necessária para a democracia também é desafiada pela história da democracia uruguaia, haja vista a profunda cultura partidária existente no país, e que "tudo indica que as preferências políticas estavam longe de serem moderadas"13 (Moreira, 1997, p. 67-68). Ao final do argumento, Moreira reconhece que a democracia no Uruguai corrobora uma das hipóteses levantadas por Tocqueville, de que a igualdade é uma condição necessária para a democracia. Para Moreira

\footnotetext{
"a democracia uruguaia foi igualitarista desde sua origem. Esse país de classes médias, urbano, moderno e alfabetizado, esse país de medianias, mesocrático, que condenou as diferenças, será ao mesmo tempo a garantia de um mundo entre iguais. Neste sentido, a democracia uruguaia parece estar mais próxima do legado clássico da teoria democrática" (Moreira, 1997, p. 69).
}

De acordo com Moreira, portanto, a cultura política uruguaia seria uma "cultura política participante", dado que a participação política é considerada um elemento central da estabilidade do regime democrático uruguaio e uma característica fundamental da cultura política do país, com profundos antecedentes históricos. 
Canzani avalia o desenvolvimento da opiniáo pública durante o governo do primeiro presidente eleito depois da volta da democracia, Julio Maria Sanguinetti (1985-1990), a partir da utilização de dados de pesquisa realizadas basicamente em Montevidéu por uma empresa privada (Equipo Consultores). O autor avalia variáveis como os principais problemas a serem enfrentados pelo governo, confiança no presidente, avaliação do governo, do parlamento, a percepção sobre a situaçáo política do país. Canzani mostra que, neste primeiro governo pós-ditadura, os políticos contavam ainda com altos índices de confiança por parte da população (Canzani, 1989).

Rossel analisa a cultura política uruguaia utilizando dados do Latinobarômetro de 1997 e propóe uma tipologia utilizando as dimensões valorativas, avaliativas e de confiança em relação ao sistema democrático e identifica três tipos de cultura política: os democratas puros; os democratas inconformados e desencantados; e os democratas débeis e não democratas. Para Rossel a existência de um grupo considerável de não democratas (12\%) representava um desafio para a democracia uruguaia (Rossel, 2002, p. 180). Já Selios analisa as mudanças ocorridas na cultura política uruguaia entre 1995 e 2004, também utilizando dados do Latinobarômetro. A autora mostra que a crise de 2002 afetou diretamente algumas percepçóes sobre o funcionamento $\mathrm{e}$ a legitimidade do sistema, embora a confiança interpessoal tenha aumentado no período. A autora atribui isso ao fato de que "quando a tradicional partidocracia e sentimento estatista foi questionada, a sociedade uruguaia apelou à sua trama social, aumentando as formas de participaçáo social e a confiança interpessoal" (Selios, 2006, p. 81) e que com a recuperaçáo econômica e as eleições de 2004 os uruguaios voltaram aos níveis anteriores de valorização da democracia e suas instituições.
Zuasnabar faz uma análise dos 30 anos de pesquisas de opinião pública realizados de forma sistemática no Uruguai. Inicialmente analisa dados sobre percepção da economia, avaliações sobre o presidente, interesse na política, apoio à democracia, tolerância à diversidade, atitudes em relaçáo à pobreza, confiança e valores de autoridade. $\mathrm{O}$ autor mostra que o apoio à democracia se mantém alto no Uruguai, mesmo durante períodos de crise, com maior valorizaçáo do respeito e da tolerância. No entanto, o achado mais preocupante da pesquisa de Zuasnabar é o aumento dos valores autoritários, mesmo após anos de crescimento econômico e melhora da qualidade de vida. O diferencial do trabalho de Zuasnabar é o acesso a dados de pesquisa de opiniáo realizados no Uruguai pela empresa Gallup em maio de 1973, o mês anterior ao golpe de Estado. Os resultados mostram que a maioria da população $(52 \%)$ estavam de acordo com as acusaçóes feitas pelos militares aos políticos (corrupção, falta de representatividade, clientelismo) e 60\% concordavam com a afirmação de que os parlamentares não se preocupavam com o bem-estar da população. Ao serem questionados sobre o enfrentamento entre militares e políticos, $34 \%$ estavam de acordo com os militares e $25 \%$ com os políticos, mostrando que boa parte da população estava de acordo com as justificativas principais do golpe de estado em 1973. O trabalho de Zuasnabar é um claro exemplo de como a utilização de pesquisas de opinião podem reforçar ou, como neste caso, rebater determinadas ideias preconcebidas, como de que a população uruguaia era contrária aos militares em 1973 (Zuasnabar, 2018b).

Por outro lado, Boidi e Queirolo utilizam dados da pesquisa Barômetro das Américas de 2010 para identificar os traços da cultura política no Uruguai, como as percepçóes acerca da crise econômica de então, valores democráticos de apoio, confiança e satisfação com o regime, 
a legitimidade da democracia e de suas instituiçôes, tolerância política, influência de fatores econômicos, da criminalidade e insegurança, identificação partidária, entre outros (Boidi; Queirolo, 2010). Este trabalho é o mais amplo entre os aqui analisados, pois além de utilizar dados da pesquisa LAPOP, trabalha com um número expressivo de variáveis de forma aprofundada, além de estabelecer comparaçóes com dados de outros países do continente. Infelizmente, os estudos de cultura política no Uruguai são minoria, limitando as interpretaçôes sobre sua estabilidade democrática a hipóteses já conhecidas e sem avançar em uma possível relação causal entre a cultura política e a estabilidade da democracia uruguaia.

\section{Conclusão}

A estabilidade da democracia é associada não só a fatores institucionais, socioeconômicos ou políticos, mas também a fatores culturais, aos valores, atitudes e comportamentos dos indivíduos em determinada sociedade. Visto que o Uruguai é considerado um exemplo de democracia estável na região latino-americana é fundamental compreender as características deste país que favoreceram a consolidação do regime democrático. Assim, este trabalho objetivou buscar as principais hipóteses explicativas dentro da ciência política uruguaia, sobre a estabilidade do regime democrático no Uruguai, sem pretensão de ser uma análise minuciosa, dado que o enfoque é basicamente a Revista Uruguaya de Ciencia Politica es pesquisadores que atuam na academia uruguaia, abrindo espaço para trabalhos futuros que abarquem também pesquisadores uruguaios que atuam no exterior. Assim, foram apresentadas algumas das principais interpretaçóes sobre a estabilidade da democracia uruguaia e sua formação histórica, o desenvolvimento destas hipóteses explicativas dentro do surgimento da disciplina de ciência política no Uruguai e os trabalhos publicados na Revista Uruguaya de Ciencia Política - a principal publicação de ciência política do país.

As primeiras explicaçóes de pesquisadores uruguaios surgiram em meados do século XX, ainda muito vinculadas à sociologia, como no caso de Real de Azúa, Solari, Errandonea e Rama. No entanto, essas interpretaçóes acabaram orientando grande parte dos estudos posteriores. A partir da formação do Instituto de Ciência Política da Universidade da República, em 1985, formam-se novos pesquisadores que apontam como causas da estabilidade a centralidade e relevância dos partidos, a formação da classe média urbana em princípios do século XX e o consenso entre as elites políticas de ambos os partidos tradicionais, o que levou à promulgação da constituição de 1918, considerada pelos autores aqui tratados como o marco inicial da poliarquia uruguaia.

Por outro lado, mesmo que os estudos sobre cultura política no Uruguai sejam majoritariamente dedicados à análise de resultados eleitorais e comportamento dos eleitores, e as pesquisas utilizadas sejam realizadas por empresas privadas de opiniáo pública, sendo poucos os estudos que utilizam as variáveis da cultura política para explicar a estabilidade da democracia, a área de cultura política no Uruguai é mais ampla do que pode parecer. É importante ressaltar que existem trabalhos importantes da área, cujo enfoque está na relevância que as tradições, crenças e valores têm como fatores de formação, reprodução e de renovação na legitimidade da democracia e em sua consequente estabilidade. Entretanto, os trabalhos aqui analisados trabalham especificamente com dados de empresas privadas, seja de empresas de opiniáo pública uruguaias, seja o Latinobarômetro ou o Barômetro das Américas. Mesmo com os avanços metodológicos e enfoques teóricos da ciência política, boa parte dos pesquisadores mantiveram-se 
associados às hipóteses explicativas das décadas anteriores, seja por sua capacidade explicativa, seja pela falta de outras hipóteses. O que as hipóteses dominantes não explicam é o porquê de países da região com características parecidas ou arranjos institucionais similares não alcançarem a mesma estabilidade.

Como exemplo, podemos citar a Argentina e a Colômbia. A Argentina, que teve um processo de colonizaçáo e modernização semelhante ao do Uruguai, conta com um sistema relativamente estável de dois partidos dominantes desde metade do século passado, o Partido Justicialista e a Unión Civica Radical, e, no entanto, atravessou reiteradas crises sociopolíticas, além de seguidos períodos autoritários (Malamud; De Luca, 2016, p. 29). Por outro lado, a Colômbia é um exemplo de sistema bipartidário com dois partidos tradicionais, os partidos Liberal e Conservador, cuja fundação ocorreu na primeira metade do século XIX, e que dominaram a política até o início dos anos 1990 (Botero; Losada; Wills-Otero, 2016, p. 341). No entanto, a competição política era restrita aos dois partidos tradicionais, o presidente nomeava os governadores e estes os alcaldes municipais, e a desigualdade social e a exclusão política acabaram propiciando o surgimento de grupos guerrilheiros, em um confronto que durou quase cinco décadas (Botero; Losada; WillsOtero, 2016, p. 340).

Historicamente também há semelhanças entre os outrora dominantes Partido Colorado no Uruguai e o Partido Liberal na Colômbia, dado que ambos foram responsáveis por incorporar a classe trabalhadora ao processo político nos seus respectivos países, no entanto, no caso colombiano, o processo ocorreu tardiamente e teve como consequência um aumento da polarização e da violência, o que não ocorreu no Uruguai (Collier; Collier, 2002, p. 308-309). Para Collier e Collier o aumento da violência da Colômbia tem raízes anteriores ao período de incorporação da classe trabalhadora, com violência rural e falta de acordo entre as elites, combinando um período de estabilidade eleitoral e instabilidade social (Collier; Collier, 2002, p. 439). Portanto, apesar dos arranjos institucionais serem necessários para a construção do regime democrático, estes não parecem ser suficientes para sua estabilidade.

No caso uruguaio é inegável a importância dos partidos políticos ou da existência de um consenso entre as elites políticas, já na primeira metade do século XX, mas esses elementos são apenas uma parte da história, que os estudos majoritários na ciência política uruguaia abordam em profundidade. Assim, sem diminuir a importância das demais explicaçóes, uma maior utilização e possível aprofundamento das hipóteses que apontam fatores culturais como fontes de estabilidade democrática poderia enriquecer o já amplo debate sobre a estabilidade da democracia no Uruguai. Por exemplo, o trabalho de Selios (2006), que identifica o aumento da confiança interpessoal em plena crise de 2002, pode ser pensado através da utilização de conceitos como "capital social" ou "comunidade cívica" (Baquero, 2013; Putnam, 1996). É possível também avançar a análise realizada tanto por Gonzalez (1993) quanto por Moreira (1997) sobre as elites políticas, identificando diferenças de gênero, de formação educacional, profissional, cruzando com as variáveis de cultura política, permitindo uma análise significativa de cada segmento da populaçáo. Do mesmo modo, a utilização do conceito de "congruência dos padróes de autoridade", desenvolvido por Eckstein (1957), poderia ser útil à análise do funcionamento dos partidos, estruturas próximas ao governo e com profunda relação com a estabilidade da democracia no país.

Em conclusão, os estudos de cultura política indicam uma relação causal entre as atitudes, valores e crenças dos indivíduos e a estabilidade do sistema político. Sendo o 
Uruguai um caso de democracia estável na América Latina, conhecer a cultura política da sociedade uruguaia permitirá ampliar e aprofundar as explicaçóes hegemônicas focadas nos partidos e nos consensos entre as elites. Em relação à contribuição deste trabalho avalio que poderá ser útil também a pesquisadores que tenham interesse na democracia uruguaia, pois apresenta uma revisão de algumas das principais hipóteses produzidas por pesquisadores uruguaios, revisão esta não encontrada anteriormente em publicaçôes nacionais. Compreender a democracia no Uruguai revela-se de profunda importância, pois é uma democracia estável em uma região marcada por golpes militares, rupturas institucionais, corrupção, acusaçóes de fraudes eleitorais, além de profundas desigualdades sociais, oferecendo algumas hipóteses acerca de como construir um regime estável.

\section{Referências}

AGUIAR, C. Algunas posibilidades de uso de encuestas de opinión en las investigaciones sobre partidos políticos: líneas y sugerencias. In: LANZARO, J. César Aguiar: Política y Sociedad en el Uruguay: recopilación de trabajos. [S. l.: s. n.], 2018a. Disponível em: https://cesaraguiar.org/algunas-posibilidades-de-uso-de-encuestas-de-opinionen-la-investigacion-sobre-partidos-politicos-lineas-y-sugerencias.php. Acesso em: 11 jan. 2021.

AGUIAR, C. La Historia y la historia: opinión pública y opinión pública en el Uruguay. In: LANZARO, J. César Aguiar: Política y Sociedad en el Uruguay: recopilación de trabajos. [S. l.: s. n.], 2018b. Disponível em: https://cesaraguiar.org/ la-historia-y-la-historia-opinion-publica-y-opinion-publica-en-el-uruguay.php. Acesso em: 11 jan. 2021.

ALMOND, G.; VERBA, S. La cultura cívica: estudio sobre la participación política democrática en cinco naciones. Tradução de José Belloch Zimmerman. Madrid: Euramérica, 1970.

BAQUERO, M. Qual democracia para a América Latina? Capital social e empoderamento são a resposta? Porto Alegre: Editora da UFRGS, 2013.

BAUZA, F. Ensayo sobre la formación de una clase média. Montevideo: El Nacional, 1876.

BENTANCUR, N.; BUSQUETS, J. M. El decenio progresista: las políticas públicas de Vázquez a Mujica. Montevideo: Fin de Siglo Editorial, 2016.

BOIDI, M. F.; QUEIROLO, R. Cultura política de la democracia en Uruguay, 2010. Montevideo: Vanderbilt University, 2010.

BOTERO, F.; LOSADA, R.; WILLS-OTERO, L. Sistema de partidos en Colombia, 1974-2014: ¿La evolución hacia el multipartidarismo? In: FREIDENBERG, F. (ed.). Los sistemas de partidos en América Latina: 1978-2015 Cono Sur y Países Andinos. Ciudad de México: Universidad Nacional Autonoma de México, 2016.

BUQUET, D. El desarrollo de la Ciencia Política en Uruguay. Política, v. 50, n. 1, p. 5-29. 2012. 
BUQUET, D.; CHASQUETTI, D. La Democracia en Uruguay: una partidocracia de consenso. Política, n. 42, p. 221-247, 2004. http://dx.doi.org/10.5354/0716-1077.2019.55540

BUQUET, D.; MORAES, J. A. Construyendo un equilibrio democrático: la reforma constitucional de Uruguay en 1917. Revista Uruguaya de Ciencia Política, v. 27, n. 1, p. 19-39, 2018. http://dx.doi.org/10.26851/rucp.27.1

CAETANO, G. Ciudadania y Nación en el Uruguay del Centenário (1910-1930): La forja de una cultura estatista. Iberoamericana Nueva Época, v. 10, n. 39, p. 161-175, 2010. https://doi.org/10.18441/ibam.10.2010.39.161-175

CAETANO, G.; RILLA, J.; PÉREZ, R. La partidocracia uruguaya: historia y teoría de la centralidad de los partidos políticos. Cuadernos del CLAEH, n. 44, v. 2, p. 37-62, 1987.

CAETANO, G.; SELIOS, L.; NIETO, E. Descontentos y “cisnes negros”: las elecciones en Uruguay en 2019. Revista Iberoamericana de Filosofía, Política, Humanidades y Relaciones Internacionales, v. 21, n. 42, p 277-311, 2019. https://doi.org/10.12795/araucaria.2019.i42.12

CANZANI, A. Restauración democrática y opinión pública en Uruguay. Revista Uruguaya de Ciencia Política, n. 3, p. 9-18, 1989.

COLLIER, D.; COLLIER, R. Shaping the Political Arena: Critical Junctures, the Labor Movement, and Regime Dynamics in Latin America. Notre Dame: University of Notre Dame, 2002.

DAHL, R. La Poliarquia: participación y oposición. Madrid: Tecnos, 1997.

DAHL, R. Sobre a democracia. Tradução Beatriz Sidou. Brasília, DF: Editora Universidade de Brasília, 2001.

D’ELÍA, G. El Uruguay Neo-Batllista: 1946-1958. Montevideo: Ediciones de la Banda Oriental, 1982.

DE SIERRA, G. As ciências sociais no Uruguai: um caso de desenvolvimento e profissionalização tardios. In: TRINDADE, $\mathrm{H}$. (org.). As Ciências Sociais na América Latina em perspectiva comparada: 1930-2005. Porto Alegre: Editora da UFRGS, 2006.

DE SIERRA, G. El Batllismo: su naturaleza y su función de de classe (conjunto de hipótesis). In: DE SIERRA, G. Gerónimo de Sierra: Cincuenta años de sociologia política - Uruguay y América Latina. Buenos Aires: CLACSO, 2017.

DE SIERRA, G. Sistema político, sistema de partidos y régimen electoral en el Uruguay. In: TAVARES, J. A. G. et al. Instituiçóes políticas comparadas do Mercosul. Rio de Janeiro: Editora FGV, 1998.

DEPARTAMENTO DE HISTORIA DEL URUGUAY. La crisis de la democracia neoliberal y la opción por la izquierda: 1985-2005. In: FREGA, A. et al. Historia del Uruguay en el siglo XX (1890-2005). Montevideo: Ediciones de la Banda Oriental, 2008.

ECKSTEIN, H. Division and Cohesion in Democracy: a Study of Norway. New Jersey: Princeton University Press, 1957. 
ERRANDONEA, A. El sistema político uruguayo: analisis de 78 años del sistema político uruguayo. Montevideo: Ediciones La República, 1994.

ERRANDONEA, A. Las clases sociales en el Uruguay actual. Montevideo: Editorial Arca, 1969. (Enciclopedia Uruguaya v. 53).

FREGA, A. La Formulación de un modelo: 1890-1918. In: FREGA, A. et al. Historia del Uruguay en el siglo XX (1890-2005). Montevideo: Ediciones de la Banda Oriental, 2008.

GARCÉ, A. La Ciencia Política en Uruguay: un desarrollo tardío, intenso y asimétrico. Revista de Ciencia Política, v. 25, n. 1, p. 232-244, 2005. http://dx.doi.org/10.4067/S0718-090X2005000100018

GARCE, A.; YAFFÉ, J. La era progresista: hacia un nuevo modelo de desarrollo. Montevideo: Fin de Siglo Editorial, 2014.

GONZALEZ, L. E. Estructuras políticas y democracia en Uruguay. Montevideo: Fundación de Cultura Universitária, 1993.

INGLEHART, R.; WELZEL, C. Modernizaçáo, mudança cultural e democracia: a sequência do desenvolvimento humano. Tradução Hilda Maria Lemos Pantoja Coelho. São Paulo: Editora Francis, 2009.

KIRCHHEIMER, O. A transformação dos sistemas partidários da Europa Ocidental. Revista Brasileira de Ciência Política, n. 7, p. 349-385, 2012. https://doi.org/10.1590/S0103-33522012000100014

LANZARO, J. Fundamentos de la democracia pluralista y estructura política del Estado en el Uruguay. Revista Uruguaya de Ciencia Política, n. 14, p. 103-135, 2004.

LANZARO, J.; DE ARMAS, G. Uruguay: clases medias y procesos electorales en una democracia de partidos. Montevidéu: Instituto de Ciencia Política, 2012. Documento de Trabalho.

LIJPHART, A. Modelos de democracia: desempenho e padróes de governo em 36 países. Tradução Roberto Franco. 2. ed. Rio de Janeiro: Civilização Brasileira, 2008.

LIPSET, S. M. Some social requisites of democracy: economic development and political legitimacy. The American Political Science Review, v. 53, n. 1, p. 69-105, 1959. https://doi.org/10.2307/1951731

MALAMUD, A.; DE LUCA, M. ¿Todo sigue igual que ayer? Continuidad y ruptura en el sistema de partidos argentino (1983-2015). In: FREIDENBERG, F. (ed.). Los sistemas de partidos en América Latina: 1978-2015 Cono Sur y Países Andinos. Cidade do México: Universidad Nacional Autonoma de México, 2016.

MALLO, S. Conflictos y armonías en épocas de refundación social y cultural: una lectura desde Carlos Real de Azúa. Revista de Ciencias Sociales, v. 25, n. 31, p 125-142, 2012. https://doi.org/10.26668/1688-5465_ anuariosociojuridico/2021.v13i1.7449

MOREIRA, C. Democracia y Desarrollo en Uruguay. Montevideo: Editorial Trilce, 1997. 
MORLINO, L. Estabilidade política. In: BOBBIO, N.; MATTEUCCI, N.; PASQUINO, G. Dicionário de Política. Brasília, DF: Editora Universidade de Brasília, 2016. v. 1.

NAHUM, B. Breve Historia del Uruguay Independiente. Montevideo: Ediciones de la Banda Oriental, 2011.

NAHUM, B. Manual de Historia del Uruguay: 1903-2000. Montevideo: Ediciones de la Banda Oriental, 2004. t. 2.

OYHANTÇABAL, G. Economía Política del Uruguay Progresista 2005-2016. Latin American Perspectives, v. 46, n. 1, 2019.

PASQUINO, G. Partidocracia. In: BOBBIO, N.; MATTEUCCI, N.; PASQUINO, G. Dicionário de Política. Brasília, DF: Editora Universidade de Brasília, 2016. v. 2.

PÉREZ, R. Cuatro antagonismos sucesivos: la concreta instauración de la democracia uruguaya. Revista Uruguaya de Ciencia Política, n. 2, p. 41-59, 1988.

PRZEWORSKI, A.; ALVAREZ, M.; CHEIBUB, J. A.; et al. O que mantém as democracias? Tradução de Cláudio Gonçalves Couto. Lua Nova, n. 40/41, p. 113-135, 1996. https://doi.org/10.1590/S0102-64451997000200006

PUTNAM, R. Comunidade e democracia: a experiência da Itália moderna. Tradução de Luiz Alberto Monjardim. Rio de Janeiro: Fundação Getúlio Vargas, 1996.

RAMA, G. W. La democracia política. Montevideo: Editorial Arca, 1969. (Enciclopedia Uruguaya, v. 44).

REAL DE AZÚA, C. El impulso y su freno: tres décadas de batllismo y las raíces de la crisis uruguaya. Montevideo: Biblioteca Artigas, 2009. (Clásicos Uruguayos, v. 179).

REAL DE AZÚA, C. Uruguay, ¿̨una sociedad amortiguadora? Montevideo: Ediciones de la Banda Oriental, 1984.

RIAL, J. Elecciones, Referéndum y Plebiscitos: Cambio en el Escenario Político Uruguayo 1992-1996. In: RIAL, J.; ZOVATTO, D. (ed.). Urnas y desencanto político: elecciones y democracia en América Latina 1992-1996. San Jose: IIDH, 1998. p. 641-689.

ROCHA, C. El desarrollo de la Ciencia Política en Uruguay (1987-2009): Temas, teorías y metodologías. 2012. Trabalho de conclusão (Graduação em Ciência Política) - Universidad de la República, Montevideo, 2012.

ROSSEL, C. Tipos democráticos y opinión pública en Uruguay. Revista Uruguaya de Ciencia Política, n. 13, p. 153-186, 2002.

RUIZ, E. El Uruguay próspero y su crisis: 1946-1964. In: FREGA, A. et al. Historia del Uruguay en el siglo XX (1890-2005). Montevideo: Ediciones de la Banda Oriental, 2008.

SELIOS, L. Los últimos diez años de la cultura política uruguaya: entre la participación y el desencanto. América Latina Hoy, v. 44, p. 63-85, 2006. https://doi.org/10.14201/alh.2485 
SCHUMPETER, J. Capitalismo, socialismo e democracia. Tradução de Ruy Jungmann. Rio de Janeiro: Editora Fundo de Cultura, 1961.

SOLARI, Aldo. Las clases sociales y su gravitación en la estructura política y social del Uruguay. Revista Mexicana de Sociología, v. 18, n. 2, p. 257-266, 1956. https://doi.org/10.2307/3537811

SOLARI, A. El desarrollo social en el Uruguay de la posguerra. Montevideo: Alfa, 1967.

VANGER, M. El país modelo: José Batlle y Ordońez 1907-1915. Montevideo: Ediciones de la Banda Oriental, 1980.

ZUASNABAR, I. César Aguiar: pionero de los estudios de opinión pública en Uruguay. In: LANZARO, J. César Aguiar: Política y sociedad en el Uruguay - recopilación de trabajos. [S. l.: s. n.], 2018a. Disponível em: https://cesaraguiar.org/cesar-aguiar-pionero-de-los-estudios-de-opinion-publica-en-uruguay.php. Acesso em: 11 jan. 2021.

ZUASNABAR, I. Treinta años de opinión pública en el Uruguay. Montevideo: Fundación Konrad Adenauer Uruguay, 2018b.

\section{Resumo}

A estabilidade da democracia e a cultura politica no Uruguai: revisäo a partir da ciência política uruguaia

O Uruguai é considerado pela literatura um dos países com maior tradição democrática na América Latina e há um grande número de trabalhos sobre o desenvolvimento e a estabilidade da democracia uruguaia. Desde a metade do século XX até as mais recentes pesquisas, as interpretaçóes dominantes apontam para a longevidade do sistema partidário e o prematuro estabelecimento da democracia "poliárquica". O objetivo do presente trabalho é realizar uma revisão de literatura sobre a democracia no Uruguai a partir da perspectiva de pesquisadores uruguaios. Mesmo com os avanços metodológicos e teóricos da ciência política, os pesquisadores mantiveram-se associados a hipóteses anteriores. Portanto, uma maior utilização e aprofundamento das hipóteses culturais como fontes de estabilidade democrática poderia enriquecer o debate sobre a estabilidade da democracia no Uruguai.

Palavras-chave: Uruguai; Democracia; Estabilidade; Ciência política; Cultura política.

\section{Abstract}

Democratic stability and political culture in Uruguay: a review from the Uruguayan political science

According to the existing literature, Uruguay is considered as one of the countries with the largest democratic tradition in Latin America, with several papers and books discussing its development and stability. From sociological essays of the mid-twentieth century up to the most recent studies in the field of political science, the dominant interpretations point to the longevity of the party system and the premature establishment of the "polyarchy" democracy. Based on the perspective of Uruguayan researchers, this paper aims to perform a literature review on democracy in Uruguay. Despite methodological and theoretical advances in political science, interpretations regarding the theme have been associated to the earliest hypothesis. Therefore, a wider use and deepening of cultural hypotheses as sources of democratic stability would enrich the debate around democratic stability in Uruguay.

Keywords: Uruguay; Democracy; Stability; Political science; Political culture. 


\section{Résumé}

La stabilité de la démocratie et la culture politique en Uruguay : une revue de la science politique uruguayenne

L'Uruguay est considéré par la littérature comme l'un des pays ayant la plus longue tradition démocratique d'Amérique Latine et il existe plusieurs études sur son développement et stabilité. De la moitié du XXe siècle aux recherches plus récentes, les interprétations dominantes soulignent la longévité du système des partis et l'établissement précoce d'une démocratie " polyarchique ». Cet article de revue propose d'analyser la démocratie en Uruguay de la perspective des chercheurs uruguayens. Malgré les avancées méthodologiques et théoriques de la science politique, les chercheurs sont restés associés aux hypothèses précédentes. Un plus grand usage et un approfondissement des hypothèses culturelles comme sources de stabilité démocratique pourraient donc enrichir le débat sur la stabilité de la démocratie uruguayenne.

Mots-clés : Uruguay ; Démocratie ; Stabilité ; Science politique ; Culture politique. 